\title{
Analysis of economic and energy consumption driving factors of China's construction industry investment in 2015
}

\author{
Zijian Zou ${ }^{1}$, Bo Bai ${ }^{2, *}$ \\ ${ }^{1,2}$ School of Environment and Energy, Peking University, Nanshan District, Shenzhen, China
}

\begin{abstract}
This paper uses the input-output model to analyse the economic and energy consumption impact of China's construction investment in 2015, and finds that it can drive economic growth of 15.11 trillion in total, with direct and indirect impacts of $27.22 \%$ and $72.78 \%$ respectively , and investment can actively promote the development of integrated services and finance and insurance sectors. Additionally, the direct energy consumption caused by the investment is $20.98 \mathrm{Mtce}$, accounting for only $1.23 \%$, while the indirect energy consumption is $1701.10 \mathrm{Mtce}$, accounting for $98.77 \%$, of which the largest energy consumption sector is the industry of Production and supply of electricity and heat, the industry of Metal smelting and rolling processing, the industry of non-metallic mineral products, indicating that the construction industry development of china has a strong dependence on traditional energy sources. In the future, we are supposed to focus on indirect energy consumption in the construction industry and formulate morae effective clean energy-saving policies.
\end{abstract}

\section{Introduction}

In economic theory, investment, consumption, and export are often compared to the troika of economic growth. Many scholars believe that there is a strong positive correlation between economic development and investment, and especially the impact of productive capital investment on economic growth.(Chaudhri,2010; Giray Gozgor,2018; Qianxue Zhang,2018; Tahsin Bakirtas,2018) A large amount of investment has effectively promoted economic development in china, and fixed asset investment indicators are often used as a barometer of China's industrial development.

Studies by scholars such as Feng Qian and others (2012) show that the impact of China's fixed asset investment on $\mathrm{CO} 2$ emissions is significantly positive. With the emergence of climate change and its questioning of human beings' pure pursuit of economic growth, curbing the growth of carbon emissions and sustainable growth have become new goals for human beings.

The Harvard China Carbon Emissions Report 2015 shows: "Industrial production and thermal power generation are the most important carbon emission sectors in China, and

\footnotetext{
*Corresponding author: bobai@pku.edu.cn
} 
they together contribute $85 \%$ of carbon emissions in china. The manufacturing and construction industries aggregate is the most significant reason for high carbon emissions in china. "However, with the deterioration of the environment and the strengthening of energy constraints, the growth of energy consumption caused by China 's fixed asset investment has become more serious. Reducing carbon emissions caused by Chinese investment is crucial for China to complete carbon reductions and build a sustainable economic development system.

China's main fixed asset investment is concentrated in the construction industry. According to the statistics of the fourth assessment report of the IPCC and the "Building Energy Consumption Research Report" released in 2016, it is known that the mean energy consumption of the global construction industry accounts for $40 \%$. The average carbon emissions reached $36 \%$. In 2015 , the energy consumption consumed by the investment in construction accounted for nearly one-third of China. The energy consumption of construction accounted for a relatively high proportion. Therefore, China's current reduction target for total emission reduction should focus on the construction industry, and the specific effect will directly affect the achievement of China's 2030 emission reduction target.

Many researchers have studied the affect of construction industry investment on economic growth and energy consumption from different perspectives. Hui Yan (2012) and others divided the construction process into four departments: manufacturing, transportation, installation, and construction of building materials. Taking Hong Kong as an example, the analysis showed that these four processes all generate greenhouse gas emissions, with the consumption of building materials producing the most greenhouse gases. Sandanayake (2015) and others carried out a hierarchical algorithm on the construction process to analyze the carbon emissions generated in the building construction. They conducted a directional analysis of the two buildings and found that the use of equipment, The carbon emissions from transportation and the use of building materials are: $19 \%, 14 \%, 67 \%$. The researches of the above scholars have paid close attention on all the energy consumption generated by the investment in the construction, but the construction industry is a typical "low-carbon, high-implicit carbon" industry. Generally, investment in the construction industry not only causes direct carbon emissions, Usually, it also affects the emissions of other sectors by providing products to other sectors. For example, the material consumption caused by the development of the construction industry will generate a lot of indirect economic growth and indirect carbon emissions. Therefore, this article will focus on the direct and indirect economic growth and energy consumption generated by the construction investment in 2015, comprehensively assess the economic and energy consumption impact of China's construction industry investment, and provide policy makers with more specific policies suggest.

Input-output analysis is an effective way to analyze the economic growth and industrial structure change of an economic system driven by demand factors such as investment and consuming.Liu (2017) and others used the IOA to assess the contribution of China's industrial $\mathrm{SO} 2$ and $\mathrm{COD}$ emission factors and found that the reduction in energy consumption in 2007-2010 was due to the structural adjustment of the construction sector. Jindao Chen et al. (2017) article found that from 1995 to 2011, the carbon dioxide emissions of construction industry in china increased by $388.7 \%$, and indirect accounted for $12.7 \%$. Indirect energy consumption is not adequately addressed in practice and theory. The studies of the above scholars are concentrated before 2012. Since the carbon emission model of the construction industry will change with the adjustment of the economic structure after 2012, this article uses the input-output table of 2015 to analyze the investment impact of the construction industry. It is of great significance to achieve economic goals and energy conservation. 


\section{Method and data sources}

\subsection{Input-output model}

The economic activities will always be accompanied by the generation of energy consumption. With the technological conditions and the industrial structure unchanged, the more output is, the more energy will be consumed. The energy consumption associated with economic activities is implied in the products. As an exogenous factor of economic growth, investment not only expands the output of the invested industry directly but also promotes the growth of other industries indirectly through the correlation between industries. Since economic activities inevitably generate energy consumption, the corresponding carbon emissions can be calculated from the carbon content contained in the investment-driven output and the required energy consumption. The total economic output driven by investment can be evaluated from the Leontief model. Assuming there are $\mathrm{N}$ departments, the Leontief model is:

$$
X=(I-A)^{-1} \times Y=\left(I+A+A^{2}+\cdots\right) \times Y=L \times Y
$$

Where

$$
A=\left[\begin{array}{lr}
\mathrm{a}_{11} \cdots \mathrm{a}_{1 n} \\
\vdots & \vdots \\
\mathrm{a}_{n 1} \cdots \mathrm{a}_{n n}
\end{array}\right], \quad Y=\left[\begin{array}{l}
\mathrm{y}_{1} \\
\vdots \\
\mathrm{y}_{n}
\end{array}\right], \quad X=\left[\begin{array}{l}
X_{1} \\
\vdots \\
X_{n}
\end{array}\right], \quad L=(I-A)^{-1}=\left[\begin{array}{lll}
l_{11} \cdots & l_{1 n} \\
\vdots & & \vdots \\
l_{n 1} \cdots & l_{n n}
\end{array}\right]
$$

In the formula (1), $\mathbf{X}$ means to the total output column vector. $\mathbf{A}$ means direct consumption coefficient matrix.I means identity matrix. L means Leontief inverse matrix. Y presents final demand column vector of the investment. The elements in the above matrix represent the sectoral matrix, such as $\mathbf{a}_{\mathbf{i j}}$ means direct consumption matrix of the $i$ Department considering unit input from the $j$ department. Take occurred investment of real assets as an input variable into matrix $\mathbf{Y}$ of formula (1), and the occurred total economic outputs $\mathbf{X}$ can be calculated.

The energy consumption produced by the unit output is defined as the energy consuming coefficient $\mathbf{F}$, and the increment value produced by the unit output is defined as the increment coefficient $\mathbf{G}$. The calculation formula is as follows.

$$
\begin{gathered}
F_{i j}=\frac{\mathrm{f}_{i j}}{X_{j}} \quad(i, j=1,2, \cdots, n) \\
\mathrm{G}_{i j}=\frac{g_{i j}}{X_{j}} \quad(i, j=1,2, \cdots, n)
\end{gathered}
$$

Where $\mathbf{X}_{\mathbf{j}}$ indicates the total output of the $j$ department, $\mathbf{f}_{\mathbf{i j}}$ means to the total energy consumption for the department $j$, and $\mathbf{g}_{\mathbf{i j}}$ means to the increment value for the department $j$.

Then, the increment value of the finance, $\mathbf{X}_{\mathbf{G}}$, which is driven by the investment $\mathbf{Y}$, can be calculated by the following formula.

$$
X_{G}=G(I-A)^{-1} \times Y=G \times L \times Y
$$

Increment value of the finance, $\mathbf{X}_{\mathbf{G}}$, which is driven by the investment $\mathbf{Y}$, can be calculated by the following formula.

$$
X_{F}=F(I-A)^{-1} \times Y=F \times L \times Y
$$

Then we introduce the energy consumption coefficient diagonal matrix $\hat{F}$, the increment value coefficient diagonal matrix $\hat{G}$ and the investment diagonal matrix $\hat{Y}$. Decompose the formula (4), (5) into direct and indirect parts, and get:

$$
\widehat{X}_{G}=\widehat{G} \times L \times \widehat{Y}=\widehat{G} \times I \times \widehat{Y}+\widehat{G} \times(L-I) \times \hat{Y}=\Delta X_{G}+\Delta \widehat{X}_{G}
$$


Where

$$
\hat{X}_{F}=\hat{F} \times L \times \hat{Y}=\hat{F} \times I \times \hat{Y}+\hat{F} \times(L-I) \times \hat{Y}=\Delta X_{F}+\Delta \hat{X}_{F}
$$

$$
\widehat{E}=\left[\begin{array}{lrr}
\mathrm{e}_{11} & \cdots & e_{1 n} \\
\vdots & & \vdots \\
e_{n n} & \cdots & e_{n n}
\end{array}\right], \hat{F}=\left[\begin{array}{llr}
f_{11} & \cdots & f_{1 \mathrm{n}} \\
\vdots & & \vdots \\
f_{n 1} & \cdots & f_{n n}
\end{array}\right] \text { and } \hat{Y}=\left[\begin{array}{lll}
y_{11} & \cdots & y_{1 \mathrm{n}} \\
\vdots & & \vdots \\
y_{n 1} & \cdots & y_{n n}
\end{array}\right]
$$

In the formulas, $\Delta X_{G}$ and $\Delta X_{F}$ refer to the direct increase in value and direct energy consumption value resulting from investment respectively. $\Delta \hat{X}_{G}$ and $\Delta \hat{X}_{F}$ refer to indirect increment in value and indirect energy consumption resulting from investment respectively.

\subsection{Data sources}

\subsubsection{Input-output table}

We construct a non-competitive input-output table 2015 according to the methods of Tian et al. (2018), which could eliminate the impact of imported goods and services ( $\mathrm{Su}$ and Ang, 2013). The total capital formation in China is the final demand Y for investment in the construction industry after excluding imported products. In addition, according to the added value in the 2015 input-output extension table and the "China's Energy Statistical Yearbook 2015", the economic added value and energy consumption intensity of each sector were obtained.

\subsubsection{Sector classification}

In order to match the classification of each sector with the energy consumption data in China Energy Statistics Yearbook 2016 (Chen and Zhang, 2010), we divided all sectors into the following 35 sectors.

\begin{tabular}{|c|c|c|c|}
\hline No. & Sector & No. & Sector \\
\hline sector1 & $\begin{array}{l}\text { Agriculture, forestry, animal } \\
\text { husbandry and fishery }\end{array}$ & sector 19 & $\begin{array}{l}\text { Electrical, machinery and } \\
\text { equipment manufacturing }\end{array}$ \\
\hline sector2 & Coal mining and washing & sector 20 & $\begin{array}{l}\text { Communication equipment, } \\
\text { computer and other electronic } \\
\text { equipment manufacturing }\end{array}$ \\
\hline sector3 & Oil and gas extraction & sector 21 & $\begin{array}{l}\text { Instrumentation and cultural office } \\
\text { machinery manufacturing }\end{array}$ \\
\hline sector 4 & $\begin{array}{l}\text { Metal Ores Mining and Dressing } \\
\text { Industry }\end{array}$ & sector 22 & Other manufacturing \\
\hline sector 5 & $\begin{array}{c}\text { Nonmetallic Mineral Mining and } \\
\text { Dressing Industry }\end{array}$ & sector 23 & Scrap \\
\hline sector6 & $\begin{array}{l}\text { Mining support services and other } \\
\text { mining products }\end{array}$ & sector 24 & $\begin{array}{l}\text { Repair of metal products, } \\
\text { machinery and equipment }\end{array}$ \\
\hline sector7 & $\begin{array}{l}\text { Food manufacturing and tobacco } \\
\text { processing }\end{array}$ & sector 25 & $\begin{array}{l}\text { Production and supply of electricity } \\
\text { and heat }\end{array}$ \\
\hline sector8 & Textile industry & sector 26 & Gas production and supply \\
\hline sector9 & $\begin{array}{l}\text { Clothing leather down and its } \\
\text { products }\end{array}$ & sector 27 & Water production and supply \\
\hline sector 10 & $\begin{array}{l}\text { Wood processing and furniture } \\
\text { manufacturing }\end{array}$ & sector 28 & Construction industry \\
\hline
\end{tabular}

Table 1. Classification 


\begin{tabular}{|c|c|c|c|}
\hline sector11 & $\begin{array}{c}\text { Paper printing and stationery } \\
\text { manufacturing }\end{array}$ & sector29 & Transportation and warehousing \\
\hline sector12 & $\begin{array}{c}\text { Petroleum processing, coking and } \\
\text { nuclear fuel processing industries }\end{array}$ & sector30 & Postal industry \\
\hline sector13 & Chemical industry & sector31 & Wholesale and retail trade \\
\hline sector14 & $\begin{array}{c}\text { Non-metallic mineral products } \\
\text { industry }\end{array}$ & sector32 & Accommodation and Catering \\
\hline sector15 & $\begin{array}{c}\text { Metal smelting and rolling } \\
\text { processing industry }\end{array}$ & sector33 & Finance and insurance \\
\hline sector16 & Metal products industry & sector34 & Real estate \\
\hline sector17 & $\begin{array}{c}\text { General and special equipment } \\
\text { manufacturing }\end{array}$ & sector35 & Integrated Services \\
\hline sector18 & $\begin{array}{c}\text { Transportation equipment } \\
\text { manufacturing }\end{array}$ & & \\
\hline
\end{tabular}

\section{Results}

\subsection{The effect of construction investment on GDP and energy consumption}

The development of the construction industry consumes lots of materials and gravel, energy, labor, etc. Simultaneously, the construction industry, transportation equipment manufacturing, special and general equipment industries, various public facilities management industries, and the provision of diversified services various departments of the national economy, such as scientific research and technical service industries, have invested a lot of production and services for project construction, thereby stimulating the economic development of these industries. According to Figure 1, it can be seen that the investment in the construction industry in 2015 boosted economic growth of 15.11 trillion yuan, of which the economic growth value directly driven was 4.11 trillion yuan, accounting for $27.22 \%$, and the indirect growth was 11.00 trillion yuan, accounting for $72.78 \%$.

The construction of various buildings involves the consumption of raw materials such as electricity, heat, cement, and steel. The input departments of these materials are all high energy consumption departments, which will further cause a large amount of energy consumption. According to Figure 2, it is known that the 1701.10Mtce energy consumption caused by the investment in the construction industry in 2015 , only 20.98 Mtce came from the direct energy consumption of the construction sector, accounting for only $1.23 \%$, and the other $1680 \mathrm{Mtce}$ energy consumption came from the indirect development of the construction industry. Energy consumption accounted for $98.77 \%$. Therefore, future policy development was supposed to focus on indirect energy consumption in the construction. This is in line with Giesekam (2015) and others who believe that the development of the construction industry will generate a large amount of indirect carbon emissions. 


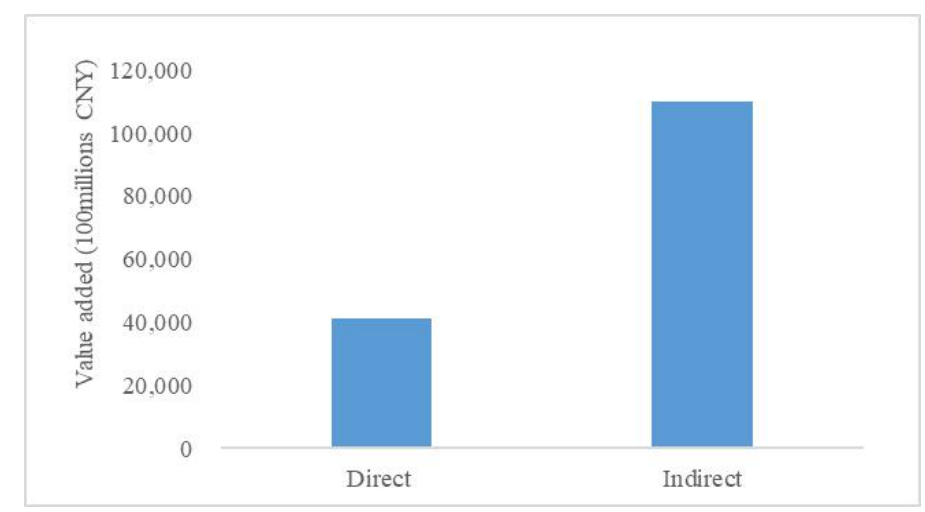

Fig. 1. GDP growth due to construction investment

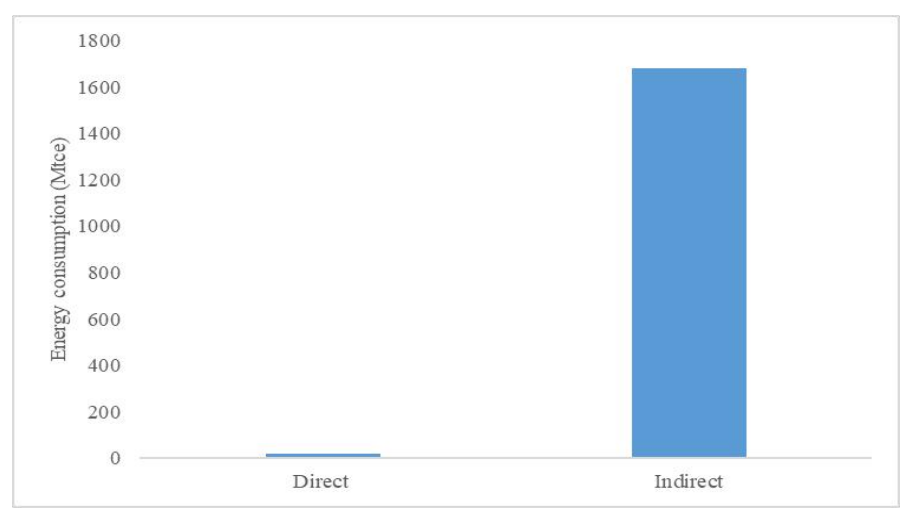

Fig. 2. Energy consumption growth due to construction investment.

\subsection{The sectoral analysis of construction investment on GDP and energy consumption}

According to Figure 3, the investment in the construction industry in 2015 can significantly boost the growth of the Construction, Integrated services, Financial Intermediation, Nonmetallic Mineral Products, and Wholesale and Retail Trades sectors. The economic growth value driven by these five sectors accounts for nearly $60 \%$. It shows that the construction investment has a positive role in promoting the integrated service industry and the financial industry. On the one hand, the construction industry is a laborintensive industry that can directly accommodate a large amount of labor. At the same time, its upstream related metal product manufacturing, machinery and equipment manufacturing, building materials, and transportation departments also absorb a large number of employees. Therefore, The construction industry indirectly accommodates a large number of employed people and contributes to alleviating employment pressure in China. On the other hand, because the construction industry has the characteristics of large investment, large resource consumption and long product formation time, for the purpose of ensure the stable development of the construction industry, China's banks, funds, trusts, insurance and other financial institutions have provided diversified financial products for the construction industry, which effectively revitalizing resources and realizing effective allocation of funds.

According to Figure 4, the sectors which have the largest energy consumption are production and supply of electricity and heat, Metal smelting and rolling processing industry, non-metallic mineral products industry, which respectively reached 1014.62 Mtce, $247.98 \mathrm{Mtce}$, and $176.52 \mathrm{Mtce}$. The total proportion reached $84.6 \%$, indicating that the 
industry's policy making efforts in these three sectors should be increased in the future. The largest proportion of the Production and Supply of Electricity and Steam sectors indicates that China still relies on traditional production methods and has a greater demand for energy such as electricity and heat. There is an urgent need to find cleaner and more efficient energy production methods. This is similar to previous research results. For instance, Jindao Chen (2017) found that investment in the construction industry will generate more significant indirect energy consumption. However, some scholars have put forward different views. For example, Chuai et al. (2015) believe that energy consumption due to investment is mainly affected by production and supply of electricity and heat, water production and supply, metal products industry. Hong et al.(2016) found that the chemical industry is the most important sector of energy consumption in the construction industry.

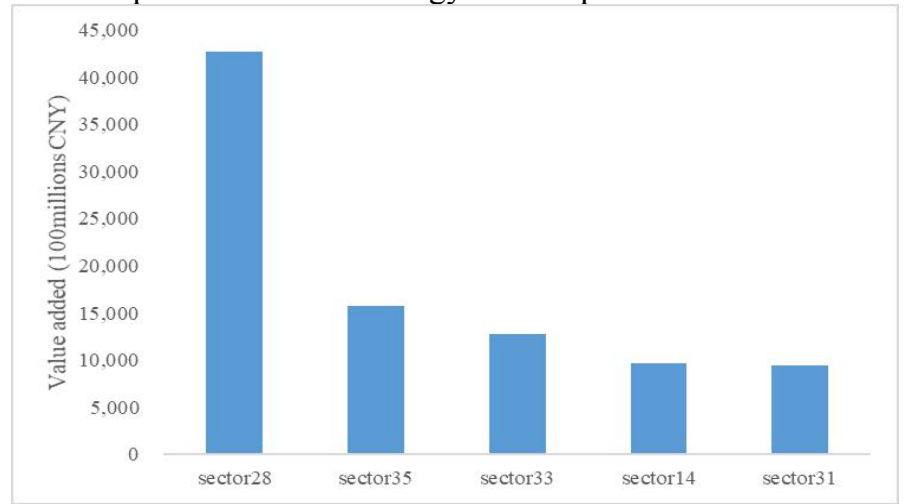

Fig. 3.The GDP growth of sectors due to construction investment

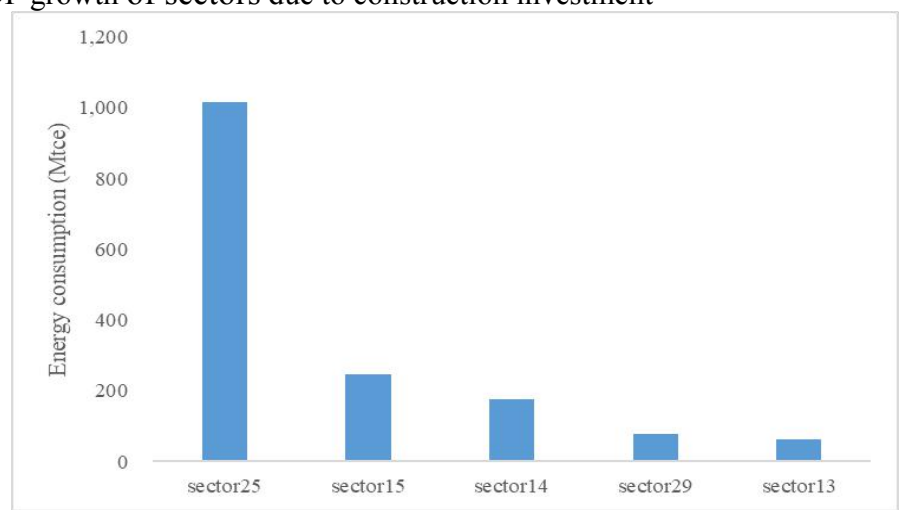

Fig. 4. The energy consumption of sectors due to construction investment

\section{Conclusions}

Our analysis focuses on the impact of China's construction investment in 2015 on China's economy and energy. By building the input-output model, it is known that the economic growth value of the construction industry investment in 2015 was 15.12 trillion yuan, of which the direct economic growth value was 4.11 trillion yuan, and the indirect economic growth value was 11.01 trillion, accounting for $27.22 \%$ and $72.78 \%$ respectively. The energy consumption caused was $1701.10 \mathrm{Mtce}$, of which direct energy consumption was $20.98 \mathrm{Mtce}$ and indirect energy consumption was $1681.12 \mathrm{Mtce}$, accounting for $1.23 \%$ and $98.77 \%$ respectively.

In addition, construction, integrated services, and financial intermediation are the top three sectors in all sectors that are most affected by investment in the construction industry, 
which account for $47.09 \%$. The top three sectors that can generate the most energy consumption are Production and Supply of Electricity and Steam, Smelting and Pressing of Metals, Nonmetallic Mineral Products, which together account for up to $84.60 \%$.

On this basis, we give the following policy recommendations:

First of all, the sectors which have the largest energy consumption due to investment in the construction industry are concentrated in traditional energy-intensive industries such as electricity and heat, indicating that China has a strong dependence on traditional energy. From the high-frequency use of non-metallic mineral products in the construction industry, we can also find that China uses more coal-consuming products. In the future, efforts should be made to optimize the energy consumption structure.

Secondly, according to the calculation results, it can be known that the indirect energy consumption due to construction investment is far greater than the direct. Therefore, future emission reduction policies were supposed to focus on the indirect energy consumption generated during the development of the construction industry. For example, improving traditional technologies, reducing material waste during construction, and increasing material usage during construction. These methods can help policymakers effectively cut back indirect energy consumption when investing in the construction industry.

\section{References}

[1] Chaudhri D P,Savings, investment, productivity and economic growth of Australia 1861-1990: some explorations. Economic Record, 76(232):55-73 (2000)

[2] Gozgor, G., Energy consumption and economic growth: New evidence from the OECD countries. Energy, 153: p. 27-34 (2018)

[3] Zhang, Q., Does one path fit all? An empirical study on the relationship between energy consumption and economic development for individual Chinese provinces. Energy,. 150: p. 527-543 (2018)

[4] Bakirtas, The relationship between energy consumption, urbanization, and economic growth in new emerging-market countries. Energy, 147: p. 110-121 (2018)

[5] Feng Qian, Hou Hexin, Li Dongyu, Foreign Direct Investment, Domestic Capital and Economic Growth in Economic Transition: Econometric Tests and Empirical Analysis Based on Chinese Time Series Data. Enterprise Economy, (4): 38-41 (2012)

[6] Hui Yan, Linda C.H.Fan,Building and environment,Qinping Chen. Greenhouse gas emissions in building construction: A case study of One Peking in Hong Kong[J] , (45)949-955 (2010)

[7] Malindu Sandanayake. Environmental emissions at foundation construction stage of buildings-Two case studies[J]. Building and environment, 95(01):189-198 (2016)

[8] Liu, L. Changes to pollutants and carbon emission multipliers in china 2007-2012: an input-output structural decomposition analysis. J ENVIRON MANAGE 203, 76-86. doi:10.1016/j.jenvman.07.061 (2017)

[9] Chen, J., et al., An empirical study on the CO 2 emissions in the Chinese construction industry. Journal of Cleaner Production, 168: p. 645-654 (2017)

[10] Tian, Y. Structural path decomposition of carbon emission: a study of China's manufacturing industry. J. Clean. Prod. 193, 563e574 (2018)

[11] $\mathrm{Su}, \mathrm{B}$. Input-output analysis of $\mathrm{CO} 2$ emissions embodied in trade: competitive versus non-competitive imports. Energy Policy 56, 83e87 (2013)

[12] Chen, G.Q. Greenhouse gas emissions in China 2007: inventory and input-outputanalysis. Energy Policy 38, 6180e6193 (2010)

[13] Giesekam.Construction sector views on low carbon building materials. Building Research \& Information, p. 1-23 (2015) 
[14] Chuai, et al., Spatiotemporal Changes of Built-Up Land Expansion and Carbon Emissions Caused by the Chinese Construction Industry. Environmental science \& technology, 49: p. 13021 (2015)

[15] Hong, J., et al., Energy use embodied in China's construction industry: A multiregional input-output analysis. Renewable and Sustainable Energy Reviews, 53: p. 1303$1312(2016)$ 